\title{
On the 2:1 Preponderance of Male Infants in the incidence of Pyloric Stenosis and in Convictions for "Shaken Baby Syndrome"
}

\section{Talbert DG*}

Institute of Reproductive and Developmental Biology, Imperial College School of Medicine, UK

\begin{abstract}
Introduction: It is known that in Pyloric Stenosis, Macrocephaly, and convictions for "Shaken Baby Syndrome"(SBS) the infant is twice as likely to be male as female. It has previously been hypothesised that the injuries assumed to prove SBS actually result from transient venous hypertension occurring during violent vomiting caused by pyloric stenosis. Macrocephaly also can be explained in terms of venous hypertension. By 1912 the pylorus had been recognized as a three part organ (antrum, canal, sphincter) independent of the stomach, but capable of cooperative action. Much of this has now been forgotten and the pylorus is considered to be merely the distal part of the stomach. Understanding of the early development and function of the pylorus is essential to understanding the development of stenosis and hence assymetrical gender distribution.
\end{abstract}

Mechanics: At birth the human pylorus is proportionately longer and thinner than in the adult. In the first few months of life, before weaning, it has to grow thicker and more compact to be powerful enough to reduce food lumps to paste before passing food onwards into the duodenum.

Testosterone stimulates contractile protein production, but not cell length, in the smooth muscle cells surrounding the pylorus. In males muscle will may grow too bulky for the current circumference and expand inwards, producing stenosis.

Conclusion: The 2:1 male gender bias in pyloric stenosis, and hence conviction rate for SBS, arises naturally from this Transient Venous Hypertension hypothesis. Hence, "SBS" trauma is a physiological phenomenon, not Imposed Trauma.

Keywords: Pyloric stenosis; Stomach; Pylorus; Digestion; Shaken baby; Macrocephalus; Smooth muscle; Antrum; Rontgen; Fluoroscopy; Testosterone; Gizzard

\section{Introduction}

There is little doubt that a genuine syndrome exists in infants, of retinal hemorrhage, subdural bleeding, and cerebral edema (brain swelling), the "triad", currently attributed to abusive shaking,. However Caffey in his original 1947 paper [1] included observation of "forceful vomiting" and "raised fontanels "prior to a fatal "Event". Study of these aspects of his observations has led to a completely different injurious mechanism hypothesis, intracranial venous hypertension. This venous hypertension arises when extreme abdominal muscle contraction, (such as in "forceful vomiting") drives blood up the IVC, SVC, and jugular veins into the intracranial venous system. Unlike true SBS there is no involvement of imposed trauma, the mechanism is entirely physiological. To denote the connection with vomiting this mechanism was termed Dysphagic Infant Death Syndrome (DIDS) [2,3].

When Miller and Miller studied convictions for SBS [4] they found that the infant involved was twice as likely to be male as female. Pyloric stenosis is also twice as frequent in males. The mechanism, indeed the very existence of the pylorus as an organ in its own right, is largely absent from modern text books. Accordingly the bulk of this paper is a recapitulation of the mechanism of the pylorus, its muscular growth, and the action of testosterone in producing the gender bias in pyloric stenosis and hence that of erroneous convictions for SBS.

In 1674, Willis recognized that proximal to the pyloric sphincter was a distinctive region which he described as the pyloric antrum. During the 1800s the stomach/pylorus was extensively studied by $\mathrm{X}$-ray fluoroscopy. The subject was continuously irradiated while the $\mathrm{X}$-ray shadow was observed on a fluorescent screen. A considerable radiological hazard to all concerned! By 1912 the pylorus had been recognized as a three part organ, Antrum, Canal and Sphincter, independent of the stomach body but capable of co-operative action. Much of this has now been forgotten, and the pylorus is considered to be merely the distal part of the stomach. The pylorus is commonly referred to as the "mill" of the stomach because it reduces lumps of swallowed food to a paste-like consistency that makes nutrients accessible in the intestine. The process is also sometimes referred to as "grinding", but mammals do not have a grinding surface, they reduce lumps by a hydrodynamic method, described below.

\section{Evolution of Various Mechanically Assisted Digestion Processes}

Figure 1 is based on data compiled by Romer [5] who compared the various forms of mechanical reduction of food item size developed independently by various species. Note however that they all inherit the "J" shape of the primitive stomach pouch in the early vertebrates.

The earliest vertebrates and jawless fishes had no stomach [5]. They had a simple intestine which was adequate to digest the micro-fauna

*Corresponding author: Talbert DG, Institute of Reproductive and Developmental Biology, Imperial College School of Medicine, Queen Charlotte's Hospital, Du Cane Road, London W12 0NN, UK, E-mail: d.talbert@imperial.ac.uk

Received May 18, 2013; Accepted June 12, 2013; Published June 14, 2013

Citation: Talbert DG (2013) On the 2:1 Preponderance of Male Infants in the incidence of Pyloric Stenosis and in Convictions for "Shaken Baby Syndrome". J Trauma Treat 2: 170. doi:10.4172/2167-1222.1000170

Copyright: (c) 2013 Talbert DG. This is an open-access article distributed unde the terms of the Creative Commons Attribution License, which permits unrestricted use, distribution, and reproduction in any medium, provided the original author and source are credited. 


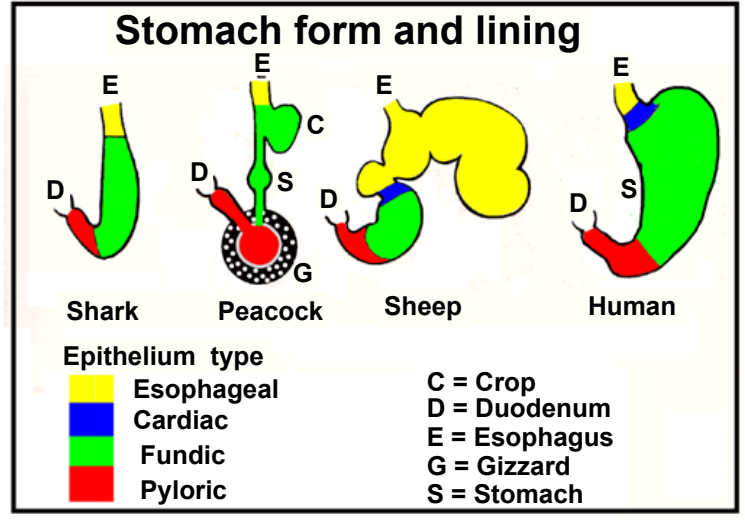

Figure 1: Evolution of various mechanically assisted digestion processes.

and micro-flora they swallowed from the water through which they were swimming. However, such simple chemical digestion could not penetrate larger items of potential food and various means of mechanical reduction evolved to increase digestive efficiency. Digestion requires time, and developing a pylorus to delay transfer into the intestine made larger food items accessible to the following intestinal processes.

Birds and mammals are descended from different ancestral lines, birds from dinosaurs and mammals from synapsids. This can be seen for example in the fact that in mammals the aorta bends to the left but in birds it bends to the right [6]. During the Triassic period, 248-206 mya (million years ago), the ancestors of mammals (Synapsids) and birds (Dinosaurs) existed simultaneously, though later, during the Jurassic Period (206 to 144 mya), the dinosaurs became much the dominant group. However, in the mass extinction of 65 mya the dinosaur line became extinct except for some reptiles, e.g. crocodiles, and birds. Of the synapsid line mammals were dominant. The prolonged independent development of mammals and birds shows up in their approaches to mechanical reduction of food particle size.

Birds initially store swallowed food in their crop, figure 1, not in their stomach. The crop is a pouch extending from the gut in a similar manner to that of the mammalian stomach. But the bird stomach is a small glandular organ which adds digestive juices as food passes through it to be ground small in the Gizzard [7]. The Gizzard is not unique to birds, crocodiles and some fish have a form of gizzard. In birds the gizzard is a large, highly muscular organ which grinds seeds etc. It has inert inner grinding surfaces that are continually renewed from below like our finger nails or horses' hooves. To further increase the grinding efficiency of the gizzard some birds may ingest grit or small stones.

In mammals the stomach arose as a pouch ahead of the intestine in which digestive juices were secreted. Herbivores, such as sheep, developed multiple stomach pouches (polygastric stomachs). Carnivores retained the original scheme of one stomach (monogastric) followed by a pylorus. They developed a highly muscularised region of the gut, just preceding the pyloric sphincter, known as the pyloric canal, figure 2. With the sphincter closed, sudden powerful contractions of the canal drive a jet of chyme back into the food in the antrum. The resulting hydrodynamic forces then tear off the softened partially digested outer layer of lumps of meat. Humans, though omnivores, share this method of the carnivores. This is often spoken of as "grinding" but that is misleading. The lining of the pyloric canal is not hardened as in birds and crocodile's gizzards; it is smooth and well lubricated. The violent turbulence induced by the pyloric canal in humans and carnivores has more of a tearing action. While the infant is on a liquid diet this action is not necessary, but pyloric muscle has to hypertrophy rapidly into the adult configuration necessary for digestive efficiency after weaning.

The independent evolution of these various forms of mechanical reduction shows the importance of such actions to digestive efficiency.

\section{The Pylorus as an Organ}

Illustrations of the pylorus are often shown in the form figure $2 \mathrm{a}$ and although the three pyloric components (Sphincter, canal and antrum) may be labeled, only the sphincter can clearly be recognized. This is because in the conditions in which the stomach shown in figure 2 a was prepared all its musculature was completely relaxed. This has led to the term "pylorus" being loosely used to describe the sphincter alone. Because the canal is not recognizable, figure $2 a$, it is widely assumed that the canal is merely a passive extension of the lower stomach. The stomach in figure $2 \mathrm{~b}$ was prepared with attention to retaining an in vivo configuration. Such universal relaxation as in figure $2 \mathrm{a}$ never occurs in vivo, the stomach and pylorus are constantly changing size and shape. The 3-part pylorus is an organ in its own right, performing a vital function in preparing food for efficient digestion. The pyloric canal lumen is normally in longitudinal folds along its whole length, whereas the rugae of the stomach lining are of random alignment except along the gastric canal.

\section{Pyloric Muscle Structure}

The Pylorus extends from the incisura angularus at the lower end of the stomach body to the duodenum, (Figure 3). The alimentary tract typically has three muscle layers. Muscle fibres in the innermost (submucosal) layer run in all directions and cause the inner surface of the lumen to slide in contact with contents but they are not relevant in the present context.

In the middle layer muscle fibres run round the gut, a circumferential orientated, circular, layer. In the pyloric canal this muscle is thicker than elsewhere in the gut. It can contract sufficiently to close the canal along its length. At its distal end this muscle layer thickens further to form a sphincter that can operate independently of the canal. Circular muscle cells in the pyloric sphincter are electrically insulated from those in the duodenum by irregular connective tissue septa [5].

The outer muscle layer is made up of longitudinal fibres, some of which continue without interruption onto the duodenum. Other longitudinal fibres penetrate down into the sphincter enabling active

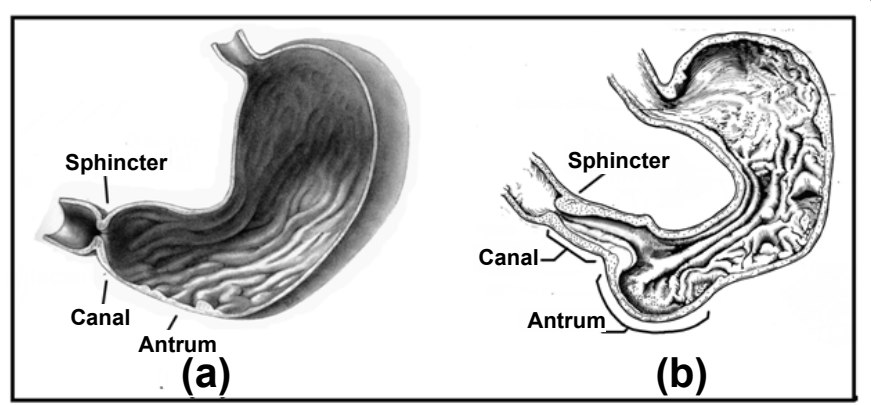

Figure 2: Current depictions of the Pylorus 
Citation: Talbert DG (2013) On the 2:1 Preponderance of Male Infants in the incidence of Pyloric Stenosis and in Convictions for "Shaken Baby Syndrome". J Trauma Treat 2: 170. doi:10.4172/2167-1222.1000170

Page 3 of 7

widening of the sphincter aperture. This facilitates emptying of any large items unaffected by gastric digestion, (beads etc.), into the duodenum following meals.

Other longitudinal fibres turn at their lower ends to join with circular muscles of the stomach body, described by Fossell as the "lower segment sling" [8-10] (Figure 4).

The incisura angularus denotes the approximate position of this U-shape "transverse band", of muscle fibres. Though not strictly a sphincter, this band is sometimes referred to as a "ring" or the "pre-pyloric sphincter". When contracted this "sling" is capable of compressing the lumen sufficiently to isolate the pylorus from the stomach. When contraction of the pyloric canal and atrium muscles drives a batch of processed food into the duodenum this isolation prevents back flow up into the stomach body.

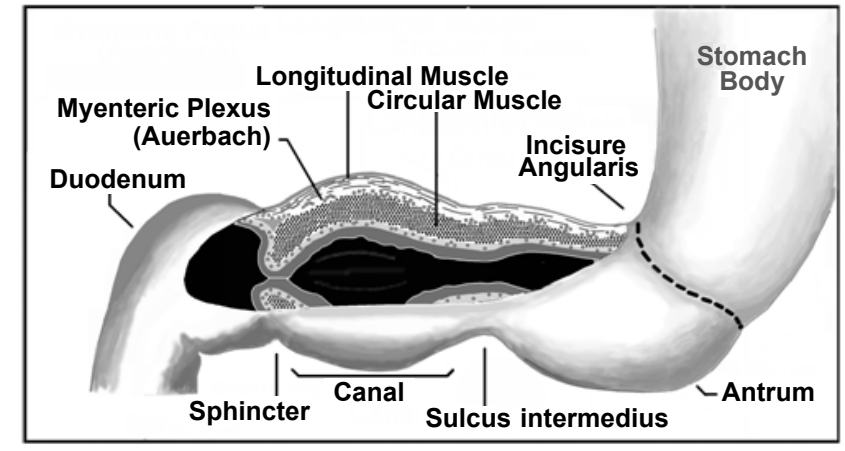

Figure 3: Pyloric muscle structure.

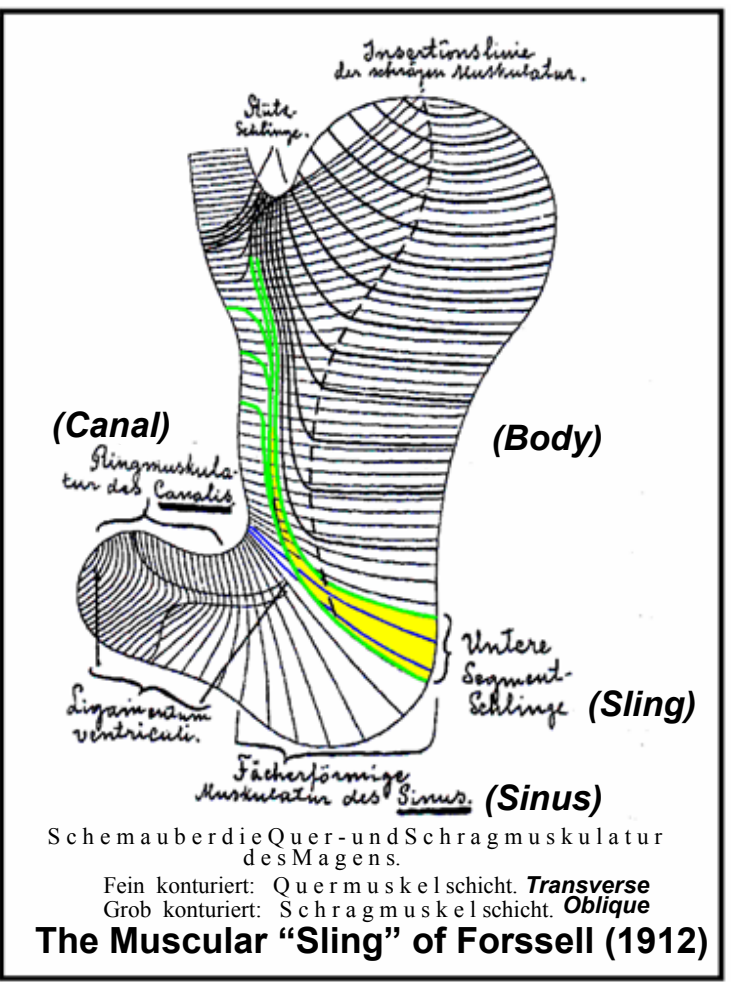

Figure 4: The Pre-pyloric "Sphincter" (The sling of Forssell)

\section{Innervation as Evidence of Functional Independence Innervations of the stomach body}

The separate development of the stomach and the pylorus is shown by their nerve supplies, blood supplies, and contraction behavior. Branches from the anterior and posterior vagus reach down the stomach only as far as incisura angularis [11].

The sympathetic fibres enter the stomach from the celiac plexus, and provide nerves to all parts.

\section{Innervation of the pylorus}

The vagus nerves of the pyloric region, originate from the hepatic branch of the anterior vagus [11]. Between the longitudinal and circular muscle layers is an extensive nerve plexus, which forms a control subsystem, the Myenteric Plexus of Auerbach [12]. The concentration of ganglion cells is high, some ten times that in the middle third of the esophagus, it is connected along the pyloric canal and it bridges over the insulating tissue between the pyloric sphincter and the duodenal "cap". This is the major nerve supply to the gastrointestinal tract and it controls local GI tract motility. The ganglia have properties similar to those in the CNS [8]. It is sometimes referred to as the Enteric Nervous System, (ENS), and the "brain" of the gut. The ENS can and does function autonomously. The CNS can send "requests" to the ENS and get "reports of progress" via the vagus but the ENS has a certain amount of independence on how these requests are carried out. For example, the pyloric canal and the sphincter cooperate but may function independently in different situations.

The pyloric system is not a simple "slave" to CNS vagal commands. Auerbach's plexus enables it to respond appropriately.

\section{Blood supply}

The canal's blood supply is from the right gastric and right gastroepiploic arteries, branches of the hepatic artery, a supply distinct from that of the stomach body, which is from the left gastric, splenic, and left gastro-epiploic arteries [13].

\section{Canal glandular complement}

The glandular population of the canal endothelium is dominated by mucous secreting glands providing lubrication for high speed jet formation.

The independent blood supplies, vagal innervations and surface (endothelium) glandular populations indicate that the stomach body and the pylorus are in effect separate organs.

\section{Pylorus Development}

The division into future stomach body and pylorus is well marked In the stomachs of embryos from 10 to $45 \mathrm{~mm}$ in length (circa 5 weeks post conception), but the pylorus is relatively long, constituting onehalf the length of the stomach [14].

The circular muscle layer of the stomach/pylorus has been observed to develop in the human embryo at the $23-41 \mathrm{~mm}$ stage, but the longitudinal muscle layer does not develop until the 41 to $75 \mathrm{~mm}$ stage [8]. By 6 months fetal development, the pylorus has proportionately reduced to about one third of the total stomach length [14], (Figure 5) In the newborn human the canal is still longer in proportion to the stomach and its wall is thinner than in the adult [15], rapid muscle growth takes place in the first few post-natal weeks.

The IPEG guidelines for surgical treatment of infantile hypertrophic 


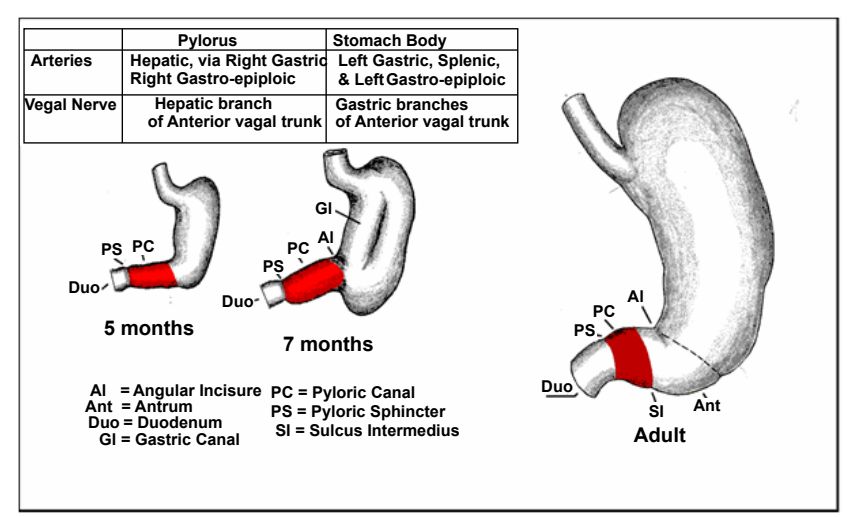

Figure 5: Changes in proportions of the (pylorus:stomach) in early pyloric development

pyloric stenosis [15] say "Pyloric dimensions with positive predictive value greater than $90 \%$ are muscle thickness greater than $4 \mathrm{~mm}$ and a pyloric channel length greater than $17 \mathrm{~mm}$. These limits may be lower in infants less than 30 days of age".

During the first few weeks of postnatal life the pyloric canal has to transform from the primitive longer, relatively thin walled, tube to a shorter, much more powerful muscular mechanism.

\section{Stomach and pyloric mechanisms}

McCrea [10] quotes several workers studying movements of the stomach by fluoroscopy from 1890 onwards. They had found that contraction of the body of the stomach occurred in waves, starting near the oesophageal opening and travelling down. Stomach waves occurred at intervals of 15 to 20 seconds with a velocity such that 3 or 4 waves could be seen simultaneously [10]. Contraction of the pyloric canal was as a whole, not a wave. He describes the actions as:-

The movements of the proximal portion of the motor segment consisted of a series of ring shaped constrictions, which commenced at a point slightly distal to the oesophageal orifice and passed to the region of the incisura angularis. On reaching this point the contraction waves appeared to cease. The pars pylorica now bulged, assuming a spherical or oval shape, and then disappeared by a process which has been aptly described as concentric contraction or systole. The systole and the diastole of the antrum recurred rythmically The two movements have been observed taking place with different rhythms. The rhythmic pyloric oscillations occurred more frequently than the stomach waves.

The action of the sling was regular rather than rhythmic and seemed to be associated with emptying the canal-atrium when reduction of a batch of food had been accomplished. Cole [16] describes the action of Forssell's sling as:-

Opposite to this deep constriction of the greater curvature appears a similar depression of the lesser curvature, of almost equal depth. Eventually the depression of the smaller and that of the greater curvature meet, so that on the screen there is seen a clear line between the shadow of the corpus and that of the antrum. Soon afterwards the shadow of the antrum disappears, its contents being emptied into the duodenum by a process of concentric contraction. The constriction three or four fingers breadth above the pylorus...has the effect of a sphincter antri which periodically cuts off the antrum pylori from the body of the stomach.

In figure $6 \mathrm{a}$ the various components are in their natural normal tone as between meals. In figure $6 \mathrm{~b}$ digestive activity has commenced with contraction of the pyloric sphincter and relaxation of antral and canal muscle tone (canal diastole). In figure $6 \mathrm{c}$ the canal has contracted (canal systole), forcing a jet of chyme back into the antrum. Phases (Figure $6 \mathrm{~b}$ and Figure $6 \mathrm{c}$ ) alternate rapidly until lumps are reduced. Then the sling contracts (Figure 6d) isolating the pylorus from the stomach body. The canal and antrum contract forcing processed chyme through a narrowly opened pyloric sphincter which retains any lumps for further processing, (not shown). The sling then relaxes allowing refilling of the canal and atrium from the stomach as in figure $6 \mathrm{~b}$ ready for the next batch to be processed. Finally, when the stomach body is empty, the pyloric sphincter is dilated (Figure 6d), allowing contraction of the antrum and canal muscles to discharge any remaining irreducible objects into the duodenum.

The stomach body contracts in waves to present Chyme to the pylorus, the pylorus contracts as a whole in a systolic/diastolic manner to strip lumps to paste.

\section{Pyloric stripping action}

The initial partial digestion in the stomach body softens the outer layer of food lumps, leaving a soft coating which has to be removed to expose the underlying food to further action. The pyloric canal pump does this by relaxing to fill with chyme from the antrum, and then forcing it back in a violent systole.

Figure 7 is drawn from radiographs made by Millen [13] of a young human subject during a barium meal. On the left the pyloric canal is relaxed and filling from the antrum (A) Millen refers to this as pyloric diastole because the pyloric canal wall muscle tone is relaxed. At its distal end the pyloric sphincter remains firmly closed. At the

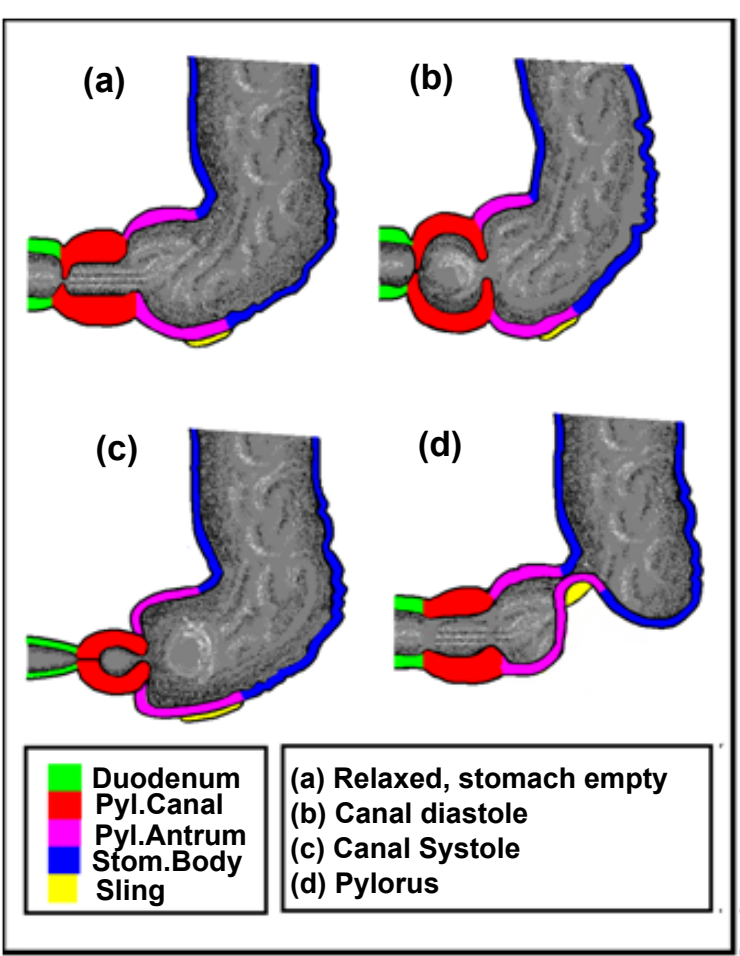

Figure 6: Summary of the Activity of the various pyloric components (a) Relaxed, (b) Pyloric diastole, (c) Pyloric systole, (d) Sling Contraction. 


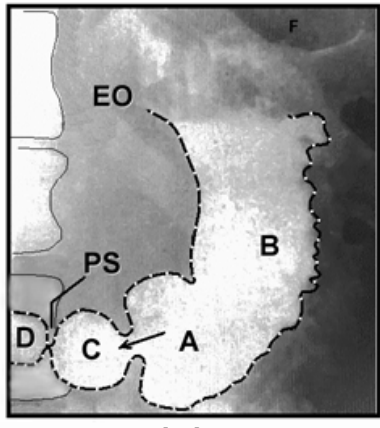

(a)

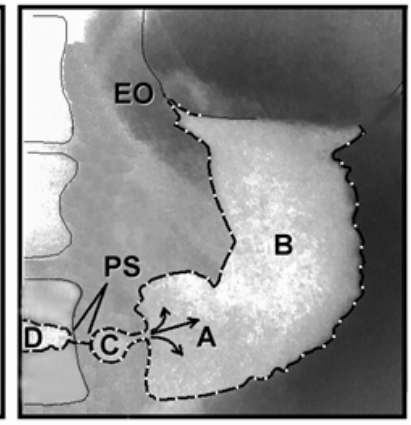

(b)
In (a) the canal circular muscle is relaxing allowing it to accept a new charge of stomach contents

In (b) with the pyloric sphincter closed the canal is powerfully contracting driving a jet back into chyme in the atrum.

$A=$ Antrum,$B=$ Stomach body, $C=$ Pyloric canal, $D=$ Duodenum, $E O=E s o p h a g a u s$, PS=Pyloric Sphincter.

Figure 7: The pyloric canal pump "blender"

canal/antrum junction the canal musculature holds the canal partially constricted, producing a spherical shape. (For a given muscle tension, the pressure in a sphere is twice that in a tube [17], so this maximizes the pressure in the following systole).

On the right the pyloric canal is contracting in late systole. This is the working phase in which the Pyloric Sphincter (PS) remains tightly closed. The canal $(\mathrm{C})$ undergoes spontaneous powerful relaxation and contraction cycles (b) and (c) in figure 6 . This causes jets of chyme to be ejected at high velocity into the current contents of the antrum (A), stripping the softened outer layers off any remaining lumps. Eventually the pylorus enters its reloading phase. The prepyloric sphincter (sling of Forssell) closes isolating the pylorus from the stomach body. The pyloric sphincter partially opens, and the canal and antrum contract, expelling their contents into the duodenum (Figure 6d). Partial opening means that any lumps greater than a certain size remain trapped for further treatment in the next cycle. Then the pyloric sphincter closes, the prepyloric sphincter opens, and the canal and antrum are recharged with another batch of stomach contents. At the end of the digestive process longitudinal muscle fibres running into the pyloric sphincter contract, dilating it and any remaining indigestible lumps and expelled into the duodenum. Millen [13] observed that:-"during the systole of the canal, the sphincter is fully contracted and the passage through it is completely occluded; that is, that during its systole the food is returned from the pyloric canal to the antrum and body of the stomach which are increased in size. West [18], though not detailing this process, describes it as violent.

In man and carnivores mechanical reduction of food is by vigorous viscous forces tearing the softened outer layers off food lumps. There is no provision for grinding as occurs in birds and reptiles. Powerful pyloric canal contractions are essential to achieve this.

\section{Smooth muscle structure and function}

In the foregoing it has been established that violent muscle power is essential for hydrodynamic food size reduction to work. Clearly muscle thickness needs to increase during the first few months of postnatal life. Challa et al. in their EM study of infants with hypertrophic pyloric stenosis [19] could find no Ultrastructural abnormalities in the muscle cells. Swollen axons were observed which they attributed to mechanical compression of the hypertrophied muscle. So what goes wrong with this process to result in hypertrophic stenosis? The answer appears to lay in the stress transmission features of the muscle cells themselves

Generally, smooth muscle cells have an elongated, tapered form, figure 8a [20]. They can be subdivided into two groups, "vascular" in blood vessels, eyes etc., and "visceral" in the digestive system. Vascular smooth muscles are extensively innervated and can respond rapidly. Visceral smooth muscles, such as those in the stomach walls, can operate independently of innervation, spontaneously setting their own rhythmic contraction pattern. The function of innervation in visceral muscles is to modulate that pattern, speeding it up or slowing it down, strengthening or weakening it.

Stomach and intestinal smooth muscle cells are extremely elongated, typically $0.2 \mathrm{~mm}$ [200 um] long and up to $8 \mathrm{um}$ wide. i.e. a length to width ratio of 25:1. Golgi saccules, mitochondria, and glycogen, and a small amount of rough-surfaced endoplasmic reticulum are largely confined to the perinuclear cytoplasm located at the poles of the centrally placed nucleus figure $8 \mathrm{c}$. Most (80-90\%) of the cell is packed with actin-myosin contractile filaments. Each smooth muscle cell is externally bounded by a basement membrane. Contiguous visceral smooth muscle cells communicate electrically through gap junctions similar to those between cardiac muscle cells [21], enabling them to cooperate as unitary muscles.

\section{Stress transmission in visceral smooth muscle}

Like voluntary muscle, visceral muscle uses an actin-myosin "motor " system $[21,22]$ to power contraction, but in smooth muscle there are many more actin filaments than myosin, 2:1 in voluntary and 12:1 in smooth [23] They are not neatly arranged as in voluntary muscle. In smooth muscle myosin occurs in long ribbons surrounded by many actin filaments. This system enables smooth muscles to have a greater range of contraction (4:1) [24] than voluntary muscles.

In addition to these active filaments there are internal structural "cables" of intermediate thickness, composed mainly of desmin. These desmin filaments occur in bundles forming a strong three dimensional intracellular network, attached to the cell surface at reinforced areas known as "dense areas" figure $8 \mathrm{a}$ and figure $8 \mathrm{~b}$. These fibres are also linked inside the cell at "dense bodies", producing a flexible redundant structure cytoskeleton, figure $8 \mathrm{c}$ and figure $8 \mathrm{~d}$. The actin filaments are attached to this cytoskeleton. Ribbons of myosin [24] alongside them can drag actin filaments connected to different dense bodies towards each other and shorten the cell. The cell volume cannot change, so the cell bulges out between the fibres running on the cell surface figure $8 \mathrm{~b}$.

The extension of voluntary muscles is limited by the range of movement of the bones to which they are attached, giving some protection against over-stretch. Visceral smooth muscles do not have such protection. Instead, the desmin fibres throughout each cell, the collagen and reticulin in cell basement membranes [21,22] and the collagen fibres running around and between them, act as a safety net. These fibres are virtually inextensible, but unless they are pulled straight their flexibility means they have little effect on cell elasticity. However, once they are pulled tight, the muscles become inextensible.

Visceral smooth muscle cells use actin/myosin filament "motors" like voluntary muscles, but in a different configuration that allows greater foreshortening. They are protected from overstretching by 


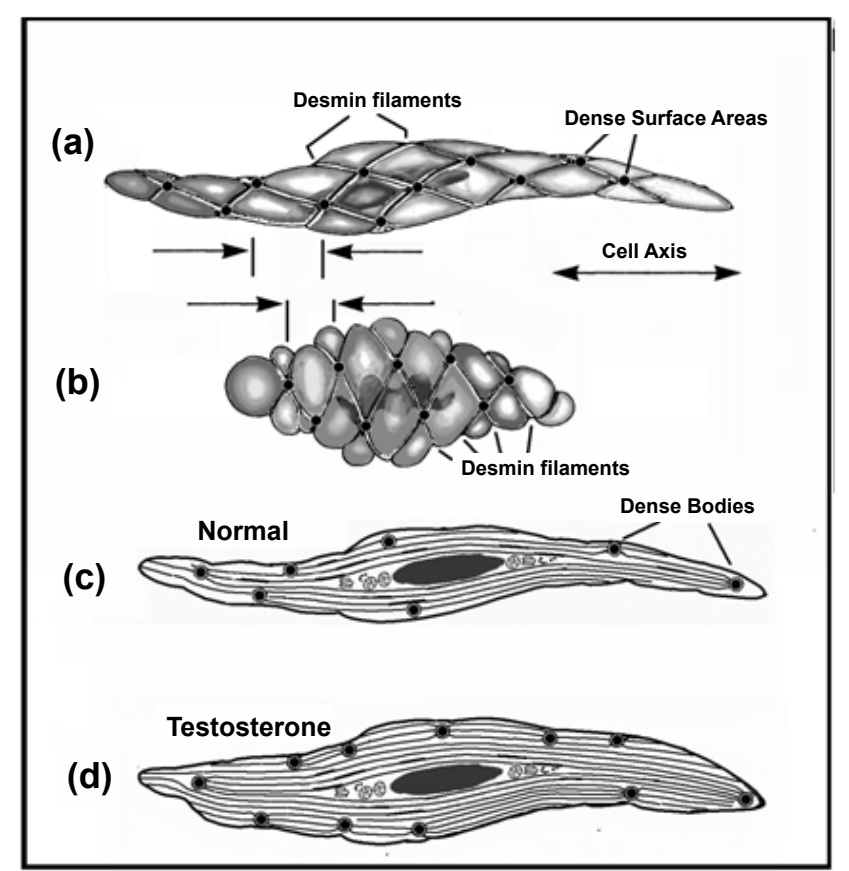

Figures (a) and (b) illustrate external views of a representative smooth muscle cell in relaxed, (a) and fully contracted state (b). (These illustrations are very foreshortened, Visceral smooth muscle cells are 25 times as long as their width)

Figure 8: Smooth muscle structure.

filaments of desmin around and within individual cells, and collagen and reticulin fibres between cells, forming a "safety net". Cells can be stretched freely until these safety nets are pulled tight, then they strongly resist further stretch.

\section{The mechanisms of Pyloric Stenosis}

Cross sections of the pyloric canal in various conditions are shown in figure 9. In figure 9a the circular muscle is relaxed and the lumen is open with longitudinal folds in the mucosa. In figure $9 \mathrm{~b}$ the circular muscle has contracted. It looks thicker because the same muscle mass is crowded into a smaller space. Similarly the longitudinal layer has been pulled in and the outer layer is puckered. In figure $9 \mathrm{c}$ the muscle volumes have increased but the circumference of the circular muscle has not increased in proportion. It is stretched tight. The greater muscle volume can only be accommodated at the expense of the lumen volume, resulting in occlusion. This has to be relieved, usually by Ramsteadt's procedure [25]. A cut is made along the pyloric canal to a depth just reaching the mucosa (Figure 9d). This relieves the tension in the circular muscle and hence the compression on the mucosa surrounding the lumen which can then open.

\section{The Influence of Testosterone in Boys}

So, pyloric stenosis is fundamentally the result of a mismatch of two processes, the pre-programmed rate of growth of the fibre "safety net" (number of cells around circular muscle circumference) and the volume of contractile proteins in individual muscle cells. The IPEG guidelines [25] specify pyloric wall muscle thickness greater than $4 \mathrm{~mm}$ or canal length greater than $17 \mathrm{~mm}$ as diagnostic of pyloric stenosis, i.e. too thick or too long. Too long suggests slow conversion from fetal to mature muscle configuration. This would suggest a genetic component in that form of stenosis. Too thick suggests a second mode of stenosis, too rapid production contractile proteins within cells. This form of stenosis would be vulnerable to the influence of testosterone. Testosterone affects muscle bulk but not maximum stretched length. (Sports drug cheats increase muscle bulk with testosterone but their muscles do not get longer and floppy). The gender bias in favour of male infants developing pyloric stenosis would be explained by accelerated contractile protein production under the influence of testosterone.

\section{Conclusion}

1. It has previously been shown (DIDS) $[2,3]$ that venous hypertension in the head, caused by powerful abdominal contractions, as in violent vomiting, can account for all the features mentioned in the definition of SBS [26,27]. Also others commonly found preceeding Events such as rashes (petichea) and accelerated head circumference growth (see Appedix).

2. Caffey's original paper [1] mentions violent vomiting and raised fontanels as being commonly observed prior to a fatal event. This makes pyloric stenosis a prime candidate for the source of pressure required to produce venous hypertension.

3. The incidence of SBS convictions and of Pyloric Stenosis both involve twice as many boys as girls. This agreement is to be expected if violent vomiting in pyloric stenosis is the cause of the syndrome.

4. Testosterone in boys would accelerate production of contractile proteins in muscle cells (muscle cell bulk) but not their length. Pyloric diameter would progress at normal preprogrammed rate. Stenosis will be expected to become critical in boys earlier than in girls.

It is concluded that the DIDS hypothesis accounts for the male preponderance in convictions for "SBS". Moreover, to dominate the overall gender bias it must be fairly common among the risk population.

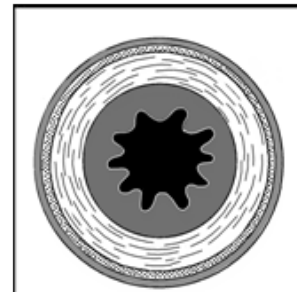

(a)

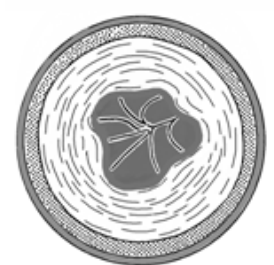

(c)

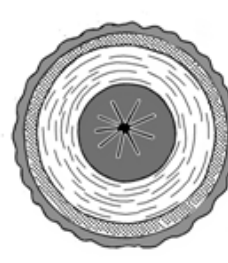

(b)

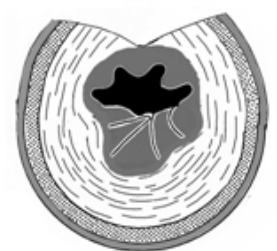

(d) (a) normal open, (b) normal constricted, (c) hypertrophied muscle bulk, muscle circumference stretched tight. (d) After Ramsteadt's procedure

Figure 9: Cross-sections of the pyloric canal under various conditions 
Citation: Talbert DG (2013) On the 2:1 Preponderance of Male Infants in the incidence of Pyloric Stenosis and in Convictions for "Shaken Baby Syndrome". J Trauma Treat 2: 170. doi:10.4172/2167-1222.1000170

\section{Appendix, the Hazards of Pyloric Stenosis}

For a full account of the mechanism of DIDS the reader is referred to reference [2] and of the resultant physiological damage to reference [3], but the essential facts are as follows. As the pyloric muscle gets thicker and the lumen gets narrower it becomes impossible for the infant to fully empty the stomach and the infant frequently vomits the remainder. Vomiting becomes increasingly violent. Eventually "projectile vomiting" occurs in which vomit may travel several feet across the room. Very high intra-abdominal pressures are required to achieve this, and these pressures are applied on blood vessels in the abdomen. Arteries have evolved to withstand pressures of $100 \mathrm{~mm} \mathrm{Hg}$ or so but veins and capillaries normally encounter only tens of $\mathrm{mm} \mathrm{Hg}$ at the most. When these vomiting pressures drive blood up the vena cavae into the head, capillaries and veins get damaged [3]. Initially water gets forced through their walls producing cerebral edema. The resulting brain swelling distends fontanels, as Caffey observed. Then, as vessels get further dilated the cell-to-cell junctions of the blood-brain barrier tear apart, allowing proteins to escape through the porous basement membranes. Finally, the basement membranes tear allowing whole blood to escape. A well known example of this is Valsalva Retinopathy in which small hemorrhages are found in the eyes following various forms of abdominal compression. The following table 1 and table 2 are reproduced from reference [2] where features of venous hypertension (DIDS) and SBS are compared before and after an Event.

The first four features in table 1 are identical in both disorders, but

\begin{tabular}{|l|l|l|}
\hline \multicolumn{1}{|c|}{ Feature } & \multicolumn{1}{c|}{ DIDS } & \multicolumn{1}{c|}{ SBS } \\
\hline Poor feeding & Explanation/ Relevance & Explanation / Relevance \\
\hline Vomiting & Pyloric Stenosis & $\begin{array}{l}\text { Observation, causing } \\
\text { Carer stress }\end{array}$ \\
\hline Lethargy & Pyloric Stenosis & $\begin{array}{l}\text { Observation, causing } \\
\text { carer stress }\end{array}$ \\
\hline Irritability & Cerebral oedema & $\begin{array}{l}\text { Observation, causing } \\
\text { carer stress }\end{array}$ \\
\hline Petechiae & Cerebral oedema & $\begin{array}{l}\text { Observation, causing } \\
\text { carer stress }\end{array}$ \\
\hline Large head & Capillary bursting during TCVH & N/A \\
\hline Floppy Head & Skull suture stretch during TVCH & N/A \\
\hline Excessive cranial weight & N/A \\
\hline Spiking Fevers & $\begin{array}{l}\text { Transient Cerebral oedema } \\
\text { disabling hypothalamic } \\
\text { temperature limiter }\end{array}$ & N/A \\
\hline
\end{tabular}

Table 1: Pre-event observations.

\begin{tabular}{|l|l|l|}
\hline \multicolumn{1}{|c|}{ Finding } & \multicolumn{1}{|c|}{ DIDS } & \multicolumn{1}{c|}{ True SBS } \\
\hline Retinopathy & Valsalva Retinopathy / TCVH & $\begin{array}{l}\text { Optic Nerve stress during } \\
\text { shaking }\end{array}$ \\
\hline $\begin{array}{l}\text { Subdural } \\
\text { haematoma }\end{array}$ & $\begin{array}{l}\text { Local bursting of veins at their } \\
\text { weakest point in the virtual } \\
\text { space below the Dura }\end{array}$ & $\begin{array}{l}\text { Torn bridging veins } \\
\text { resulting from relative } \\
\text { brain skull movement }\end{array}$ \\
\hline Diffuse haematoma & $\begin{array}{l}\text { Capillaries can burst anywhere } \\
\text { in brain, intra parenchymal } \\
\text { bleeds }\end{array}$ & N/A \\
\hline $\begin{array}{l}\text { Cerebral mal- } \\
\text { function }\end{array}$ & $\begin{array}{l}\text { Temporary or permanent axon } \\
\text { malfunction with changed ionic } \\
\text { concentrations }\end{array}$ & Rupture of brain structure \\
and blood supply
\end{tabular}

Table 2: Post-event features. petechiae, enlarged and/or floppy heads etc are observations unique to DIDS.

\section{References}

1. Caffey J (1974) The whiplash shaken infant syndrome: manual shaking by the extremities with whiplash-induced intracranial and intraocular bleedings, linked with residual permanent brain damage and mental retardation. Pediatrics 54 396-403.

2. Talbert DG (2012) Pyloric Stenosis as a Cause of a Venous Hypertensive Syndrome Mimicing True Shaken Baby Syndrome. J Trauma Treatment 1:102.

3. Talbert DG (2012) Is "Shaken Baby Syndrome" the Malignant Peak of a "Benign Hydrocephalus of Infancy " Iceberg? J Trauma Treatment 1: 149.

4. Miller R, Miller M (2010) Overrepresentation of males in traumatic brain injury of infancy and in infants with macrocephaly: further evidence that questions the existence of shaken baby syndrome. Am J Forensic Med Pathol 31: 165-173.

5. Romer AS, Parsons TS (1977) Digestive System. The Vertebrate Body. (5edn), W.B. Saunders, Philadelphia

6. Romer AS, Parsons TS (1977) Circulatory System. The Vertebrate Body. W B Saunders company, Philadelphia.

7. Caceci T Exercise 22: Avian Digestive System

8. Alarotu $H$ (1956) The neuromuscular anatomy and physiology of the pylorus Acta Paediatrica 45: 14-18

9. Forssell G (1912) Ueber die Beziehung der auf den Rontgenbildern hervortrenden Formen des menschlichen Magens zur Muskelarchektur der Magenwand. Muencchener Medizinische Wochenschrift Ixi 61:1588-1592.

10. McCrea ED, McSwiney BA, Morison JW, Stopford JSB (1924) The Normal Movements of the Stomach. Quarterly J Exper Physiology 14: 379-397.

11. McCrea ED (1924) The Abdominal Distribution of the Vagus. J Anat 59: 18-40.

12. Wikipedia. Auerbach's Plexus.

13. Millen JW (1944) The Pyloric Canal. Ulster Med J 13: 156-122.

14. Lewis FT (1912) The form of the stomach in human embryos with notes upon the nomenclature of the stomach. Am J Anatomy 13: 477-503.

15. (2012) Guidlines for Surgical Treatment of Infantile Hypertrophic Pyloric Stenosis. 1-4.

16. Cole LG (1911) The complex motor phenomena of various types of unobstructed gastric peristalsis. Archives of the Roentgen Ray 16: 242-247.

17. Sircar S (2008) General Physiology. In: Sircar S, editor. Principles of medical physiology. 1 ed. Stuttgart: Thieme; 3-18.

18. West JB (1990) Gastrointestinal System. Physiological Basis of Medical Practice. (12edn).

19. Challa VR, Jona JZ, Markesbery WR (1977) Ultrastructural observations of the myenteric plexus of the pylorus in infantile hypertrophic pyloric stenosis. Am J Pathol 88: 309-322.

20. Cormack DH (1987) Muscle Tissue. In: Ham's Histology. ( $9^{\text {th }}$ edn). J B Lippincott, Philadelphia.

21. Aguilar HN, Mitchell BF (2010) Physiological pathways and molecular mechanisms regulating uterine contractility. Hum Reprod Update 16: 725-744.

22. Gray H, Warwick R, Williams RL (1973) Myology. Gray's Anatomy. (35 $5^{\text {th }}$ edn) Edinburgh: Longman.

23. Sircar S (2008) Functional Anatomy of the Neurouscular System. In: Sircar S editor. Principles of Medical Physiology. 57-65. Stuttgart:Thieme.

24. Xu JQ, Harder BA, Uman P, Craig R (1996) Myosin filament structure in vertebrate smooth muscle. J Cell Biol 134: 53-66.

25. Guidelines for Surgical Treatment of Infantile Hypertrophic Pyloric Stenosis International Pediatric Endosurgery Group (IPEG) IPEG 2002.

26. (1993) American Academy of Pediatrics Committee on Child Abuse and Neglect: Shaken baby syndrome: inflicted cerebral trauma. Pediatrics 92: 872 875 .

27. American Academy of Pediatrics: Committee on Child Abuse and Neglect (2001) Shaken baby syndrome: rotational cranial injuries-technical report Pediatrics 108: 206-210. 